\title{
BMJ Open Stroke incidence and subtypes in Aboriginal people in remote Australia: a healthcare network population- based study
}

\begin{abstract}
Anna H Balabanski (D , , ${ }^{1,2}$ Kendall Goldsmith, ${ }^{1}$ Blake Giarola, ${ }^{3}$ David Buxton, ${ }^{1}$ Sally Castle, ${ }^{4}$ Katharine McBride, ${ }^{4}$ Stephen Brady, ${ }^{5}$ Amanda G Thrift (D) , Judith Katzenellenbogen (10 , ${ }^{6}$ Alex Brown, ${ }^{4,7}$ James Burrow, ${ }^{8}$ Geoffrey A Donnan, ${ }^{9}$ Simon Koblar, ${ }^{10}$ Timothy J Kleinig $^{1,10}$
\end{abstract}

To cite: Balabanski AH, Goldsmith K, Giarola B, et al. Stroke incidence and subtypes in Aboriginal people in remote Australia: a healthcare network populationbased study. BMJ Open 2020;10:e039533. doi:10.1136/ bmjopen-2020-039533

- Prepublication history for this paper is available online. To view these files, please visit the journal online (http://dx.doi org/10.1136/bmjopen-2020039533).

Received 18 April 2020 Revised 27 August 2020 Accepted 03 September 2020

Check for updates

(C) Author(s) (or their employer(s)) 2020. Re-use permitted under CC BY-NC. No commercial re-use. See rights and permissions. Published by BMJ.

For numbered affiliations see end of article.

Correspondence to Dr Timothy J Kleinig; timothy.kleinig@sa.gov.au

\section{ABSTRACT}

Objectives We aimed to compare the incidence, subtypes and aetiology of stroke, and in-hospital death due to stroke, between Aboriginal and non-Aboriginal people in Central Australia, a remote region of Australia where a high proportion Aboriginal people reside $(40 \%$ of the population). We hypothesised that the rates of stroke, particularly in younger adults, would be greater in the Aboriginal population, compared with the non-Aboriginal population; we aimed to elucidate causes for any identified disparities.

Design A retrospective population-based study of patients hospitalised with stroke within a defined region from 1 January 2011 to 31 December 2014.

Setting Alice Springs Hospital, the only neuroimagingcapable acute hospital in Central Australia, serving a network of 50 healthcare facilities covering $672000 \mathrm{~km}^{2}$. Participants 161 residents ( $63.4 \%$ Aboriginal) of the catchment area admitted to hospital with stroke.

Primary and secondary outcome measures Rates of first-ever stroke, overall (all events) stroke and in-hospital death.

Results 0 121 residents with first-ever stroke, 61\% identified as Aboriginal. Median onset-age (54 years) was 17 years younger in Aboriginal patients $(p<0.001)$, and age-standardised stroke incidence was threefold that of non-Aboriginal patients (153 vs 51 per 100000 , incidence rate ratio $3.0,95 \% \mathrm{Cl} 2$ to 4 ). The rate ratios for the overall rate of stroke (first-ever and recurrent) were similar. In Aboriginal patients aged $<55$ years, the incidence of ischaemic stroke was 14-fold greater (95\% Cl 4 to 45), and intracerebral haemorrhage 19fold greater $(95 \% \mathrm{Cl} 3$ to 142$)$ than in non-Aboriginal patients. Crude prevalence of diabetes mellitus $(70.3 \%$ vs $34.0 \%, p<0.001)$ and hypercholesterolaemia $(68.9 \%$ vs $51.1 \%, p=0.049$ ) was greater, and age-standardised in-hospital deaths were fivefold greater (35 vs 7 per 100 $000,95 \% \mathrm{Cl} 2$ to 11) in Aboriginal patients than in nonAboriginal patients.

Conclusions Stroke incidence (both subtypes) and in-hospital deaths for remote Aboriginal Australians are dramatically greater than in non-Aboriginal people, especially in patients aged $<55$ years.

\section{Strengths and limitations of this study}

- This study represents the largest sample of stroke incidence, subtypes and in-hospital death in Aboriginal Australians, including the first curated data on stroke incidence within a defined healthcare network region in remote Aboriginal Australians

- Well-defined population-based methodology, with rigorous case analysis, allowed more accurate stroke ascertainment and phenotyping than previous coding-based studies.

- Alice Springs Hospital is the referral centre receiving patients from 50 primary healthcare facilities (which all lack neuroimaging capability), allowing for a population-based study involving a large catchment area of Central Australia.

- As a retrospective study, results may be affected by incomplete data records and subject to bias.

- Underpresentation from individuals in remote communities (ie, due to mild stroke syndromes or out-of-hospital deaths) may have underestimated disparities in the incidence of stroke between Aboriginal and non-Aboriginal people.

\section{INTRODUCTION}

Stroke is the leading cause of disability and the third largest cause of death in Australia. ${ }^{1}$ Aboriginal and Torres Strait Islander (hereafter referred to as Aboriginal) Australians comprise $3.3 \%$ of the Australian population but have disproportionately greater morbidity and mortality rates. Life expectancy is 8 years less than among non-Aboriginal Australians ${ }^{12}$ and in remote and very remote areas the lifeexpectancy gap is 14 years, reflecting further disadvantage of remote and very remote Aboriginal residents compared with their non-remote counterparts. ${ }^{12}$

These disparities highlight limitations to date in the translation of research into improved health outcomes for Aboriginal 


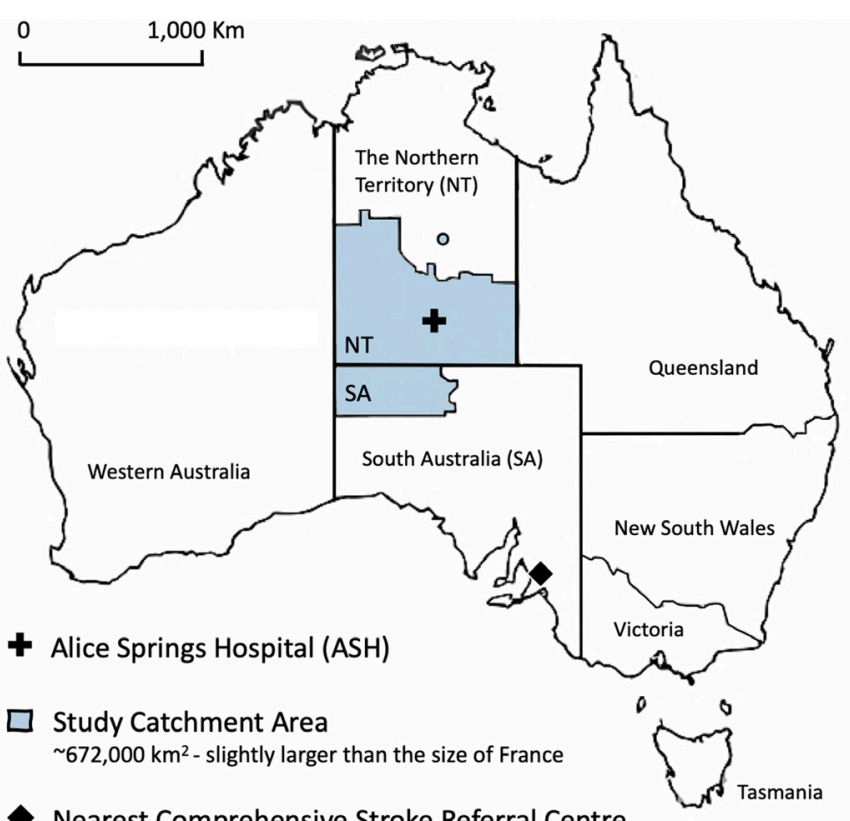

Nearest Comprehensive Stroke Referral Centre

Figure $1 \mathrm{ASH}$. Study catchment area $\sim 672000 \mathrm{~km}^{2}$ - slightly larger than the size of France. Nearest comprehensive stroke referral centre.

Australians. ${ }^{3}$ This has been attributed to research being performed 'on' rather than in partnership with Aboriginal Australians, as well as a failure to recognise and address the catastrophic effects of colonisation on health outcomes for Aboriginal Australians. ${ }^{34}$ There is increasing awareness of the need for research designed in partnership with and in response to the priorities of Aboriginal Australians, to redress this. ${ }^{4}$ High-quality evidence, taking into account social, cultural, geographical and institutional factors to inform effective healthcare reform and policy development, is urgently required. ${ }^{4}$

Published data on stroke among Aboriginal Australians are sparse. ${ }^{5-10}$ Stroke-related mortality rates in Aboriginal Australians in 2015 were reported to be 1.5-fold that of non-Aboriginal Australians with a burden of disease (disability-adjusted life years) of 2.3-fold that of nonAboriginal Australians. ${ }^{11}$ Due to limitations of administrative data with potential for inaccuracies in classification of Indigenous status and cause of death, these disparities are likely underestimated. The only prospective population-based stroke incidence study in Aboriginal Australians provided evidence of excess rates in young people. ${ }^{5}$ However, estimates of incidence were imprecise, relying on only 13 Aboriginal patients with stroke, and while regional areas were covered, remote populations were not. ${ }^{5}$ Retrospective and linked-data studies indicate greater incidence and prevalence of stroke in Aboriginal people ${ }^{6-8}$ but comprise insufficient detail for in-depth stroke phenotyping required to inform targeted primary and secondary prevention. ${ }^{910}$

Alice Springs Hospital (ASH) is the major acute hospital (186-beds) for Central Australia, serving a vast catchment area spanning approximately 1.6 million $\mathrm{km}^{2}$. ASH is the only neuroimaging-capable referral centre for all fifty primary healthcare facilities in the region, including the smaller (20-bed) Tennant Creek Hospital, $509 \mathrm{~km}$ distant by road. It is geographically isolated from other health services; flight distances are $1319 \mathrm{~km}$ from the nearest tertiary stroke centre and $1041 \mathrm{~km}$ from another CT scanner (Katherine, Northern Territory). There are no on-site neurologists or stroke specialists. Due to probable near-complete region-wide case ascertainment and a high proportion of Aboriginal people ( $40 \%$ of the resident population), ASH is ideally suited for a quasi-populationbased stroke incidence study in remote-living Aboriginal Australians. This study is part of a research programme of stroke epidemiology in the South Australian and Northern Territory regions of Australia, initiated and endorsed by Aboriginal stakeholders.

\section{AIMS}

Using rigorous case evaluation based on all available clinical and neuroimaging data, we aim to compare the incidence of stroke and types of stroke, and stroke-related death between Aboriginal and non-Aboriginal Australians hospitalised with acute stroke within a defined region of Central Australia.

\section{METHODS}

\section{Study period}

The study comprises patients admitted from 1 January 2011 to 31 December 2014, inclusive. This study period was selected as it directly predated the introduction of a Stroke Protocol at ASH, thereby providing a baseline for measuring the efficacy of subsequent stroke interventions.

\section{Study population}

All ASH stroke admissions among residents of Alice Springs, Tennant Creek and the Anangu Pitjantjatjara Yankunytjatjara lands (figure 1) comprising a total population of 41562 people ( $40 \%$ Aboriginal) over approximately $672000 \mathrm{~km}^{2}$ (slightly larger than the size of France). We selected this smaller region within the ASH greater catchment area as this area comprises a distinct geographical region. Additionally, we determined that patients residing in this region would be most unlikely to present to other health services, allowing for precision in the calculation of incidence rates. ${ }^{12}$ Non-residents were excluded. ASH is the sole hospital serving this area that has a brain imaging facility. All patients from these regions with suspected stroke are routinely transferred from fifty primary healthcare facilities (including public primary healthcare centres, Aboriginal Community Controlled Health Services, Tennant Creek Hospital and privately managed general practices) to ASH.

\section{Definition}

WHO clinical definition of stroke was used, inclusive of ischaemic stroke (IS), spontaneous intracerebral haemorrhage (ICH) and non-traumatic subarachnoid 
haemorrhage. Transient ischaemic attack, spontaneous extradural haematoma, subdural haematoma and traumatic haemorrhage were excluded. ${ }^{13}$

\section{Data collection}

Stroke admissions were identified using the International Classification of Diseases, 10th revision, Australian Modification (ICD-10-AM) codes I60, I61, I62.9 I63 and I64 (all diagnosis fields) from hospital administrative databases. Case information was extracted from ASH and tertiary hospital medical records for patients aged $\geq 18$ years using a prespecified data extraction template and managed electronically. Risk factors were identified from medical records from ASH and from supplementary records from primary healthcare providers and tertiary referral centres, where available. Records examined included patient selfreported history, documented physician diagnoses prior to or during admission, in-hospital clinical parameters and laboratory results (ie, total cholesterol concentration documented on the electronic health records). When not identified, risk factors were recorded as absent. All neuroimaging was reviewed and in-hospital deaths recorded. All authors had full access to the study data, including statistical reports and tables.

\section{Case assessment}

Clinical and radiological information was examined by the same senior vascular neurologist (TJK) to assign final stroke diagnosis and aetiological classification using the Trial of ORG 10172 in Acute Stroke Treatment ${ }^{14}$ and structural vascular lesions, medication, amyloid angiopathy, systemic disease, hypertension, or undetermined (SMASH-U) $\mathrm{ICH}^{15}$ criteria. We included only definite (evident on neuroimaging) or probable strokes (rapidonset focal neurological disturbance lasting $>24$ hours or leading to death, without a non-stroke cause identified) ${ }^{13}$ Recurrent stroke was defined as a stroke event in a patient with a history of prior stroke during or before the study period. All others were deemed first-ever (incident) stroke. In-hospital death related to stroke was defined as death during hospital admission as a direct result of, or due to the complications of stroke. These deaths were used as numerators for population-based in-hospital death rates and for case fatality ratios.

\section{Calculation of rates}

Incidence (first-ever), attack (all strokes), recurrent stroke and in-hospital death rates were calculated per 100000 /year, world-population-standardised using the direct method. ${ }^{16}$ Case-fatality (incident strokes resulting in death as a proportion of all incident stroke events) was also calculated. CIs were calculated using the Poisson distribution. The population-at-risk was identified from the 2011 Census data of the study catchment area (figure 1). Comparisons were performed using Student's t-test (continuous variables), Mann-Whitney U test (nonparametric variables), $\chi^{2}$ test or Fisher's exact test (binary outcomes).
Waiver of consent was granted.

\section{Patient and public involvement}

This study represents one component of the four-part 'South Australian and Northern Territory Stroke Study: Stroke in Aboriginal and Torres Strait Islander people; incidence, mortality and disease burden' which was designed in response to an identified need to determine burden of disease, outcomes and areas for service development for Aboriginal and Torres Strait Islander Australians. This research programme was prompted by a senior Aboriginal researcher $(\mathrm{AB})$ and conducted by the research team in partnership with relevant Aboriginal stakeholders. Thus, Aboriginal health councils, Aboriginal research units, medical services, communities and Elders were consulted during the design, conduct and reporting of the study. As waiver of consent was obtained, it was not appropriate or possible to involve patients in the design, conduct or reporting of our research. Data management has been conducted in accordance with the CARE Principles for Indigenous Data Governance, which recommend data governance is designed to ensure Indigenous Peoples' authority to control, responsibility for, and capacity to derive collective benefit from the data. ${ }^{17}$

\section{RESULTS}

\section{Ascertainment}

Of 274 coding-derived events, 43 cases were non-stroke (positive predictive value for coding of $84 \%, 95 \%$ CI $80 \%$ to $88 \%$ ). Thirty cases were duplicates, 34 cases were non-residents, 40 cases were recurrent strokes and 6 case files were unlocatable. The remaining 121 patients with first-ever stroke were included in the analysis.

\section{Incidence}

During the study period, 121 residents $(61.2 \%$ Aboriginal) were admitted with first-ever stroke (table 1). Median age at stroke occurrence in Aboriginal patients (54 years) was 17 years younger than that for nonAboriginal patients $(\mathrm{p}<0.001)$. The sex distribution ( $47 \%$ male) was similar between populations. Agestandardised stroke incidence in the Aboriginal population was threefold greater than in the non-Aboriginal population ( $95 \%$ CI 2 to 4 ; table 2). In those aged $<55$ years, this cut-off approximating the median age of Aboriginal people in our study, the age-standardised incidence of stroke in the Aboriginal population was near-fourteen-fold greater than in the non-Aboriginal population (table 3 ).

\section{Attack rates}

The overall rate of stroke was threefold greater in the Aboriginal population than in the non-Aboriginal population (table 4), a similar ratio to first-ever strokes. Of the total number of patients presenting with stroke aged less than 65 years, 21 (28\%) Aboriginal patients presented with recurrent stroke compared with 
Table 1 Demographics, risk factor profile and in-hospital deaths among patients with first-ever stroke (2011-2014)

\begin{tabular}{|c|c|c|c|}
\hline Variable & $\begin{array}{l}\text { Aboriginal } N(\%) \\
n=74\end{array}$ & $\begin{array}{l}\text { Non-Aboriginal N (\%) } \\
\mathrm{n}=47\end{array}$ & P value* \\
\hline Male & $35(47.3)$ & $22(46.8)$ & 1.0 \\
\hline \multicolumn{4}{|l|}{ Age } \\
\hline Median (Q1, Q3), years & $54(48-66)$ & $71(58-80)$ & $<0.001$ \\
\hline$<55$ years $(n)$ & $40(54.1)$ & $7(14.9)$ & $<0.001$ \\
\hline \multicolumn{4}{|l|}{ Risk factors $†$} \\
\hline Atrial fibrillation & $12(16.2)$ & $7(14.9)$ & 0.845 \\
\hline Diabetes mellitus & $52(70.3)$ & $16(34.0)$ & $<0.001$ \\
\hline Hypertension & $60(81.1)$ & $32(68.1)$ & 0.102 \\
\hline Obesity & $10(13.5)$ & $6(12.8)$ & 0.906 \\
\hline Smoker & $14(18.9)$ & $10(21.3)$ & 0.751 \\
\hline Hypercholesterolaemia & $51(68.9)$ & $24(51.1)$ & 0.049 \\
\hline Ischaemic heart disease & $22(29.7)$ & $10(21.3)$ & 0.304 \\
\hline Rheumatic heart disease & $5(6.8)$ & $1(2.1)$ & 0.403 \\
\hline \multicolumn{4}{|l|}{ In-hospital death } \\
\hline Case fatality & $17(23.0)$ & $5(10.6)$ & 0.086 \\
\hline Crude rate of death $\ddagger$ & 25 & 5 & 0.001 \\
\hline Age-standardised rate of death $\ddagger$ & 35 & 7 & $<0.001$ \\
\hline
\end{tabular}

*All $p$ values for comparison are based on crude measurements, unless otherwise stated.

†Risk factors identified from medical records, and includes history, or newly diagnosed from clinical parameters or laboratory results. †Rate per 100000 population/year.

one $(5 \%)$ non-Aboriginal patient. Overall, the agestandardised rate of recurrent stroke in the Aboriginal population was almost 2-fold that in the non-Aboriginal population (59 vs 32 per 100000 /year, incidence rate ratio $1.8,95 \%$ CI 1.2 to 2.8 ).

\section{Risk factors}

All conventional risk factors for stroke, except smoking, appeared more frequent in Aboriginal than
non-Aboriginal patients, but estimates were only statistically different for diabetes mellitus $(70.3 \%$ vs $34.0 \%$, $\mathrm{p}<0.001)$ and hypercholesterolaemia $(68.9 \%$ vs $51.1 \%$, $\mathrm{p}=0.049$; table 1 ).

\section{Investigations and stroke subtypes}

Neuroimaging was performed in $100 \%$ of patients with first-ever stroke; CT brain was performed in $98 \%$, MRI in $11 \%$ and both in $10 \%$. Of 88 patients with IS,

Table 2 Age-specific incidence rates of first-ever stroke (per 100000 population/year) in the Alice springs catchment area (2011-2014)

\begin{tabular}{|c|c|c|c|c|c|c|c|c|c|c|c|}
\hline \multirow[b]{2}{*}{ Age, years } & \multicolumn{2}{|c|}{ Population at risk } & \multicolumn{3}{|c|}{ Aboriginal } & \multicolumn{3}{|c|}{ Non-Aboriginal } & \multicolumn{3}{|c|}{ Incidence rate ratio (IRR) } \\
\hline & Aboriginal & $\begin{array}{l}\text { Non- } \\
\text { Aboriginal }\end{array}$ & $\mathbf{n}$ & Rate & $95 \% \mathrm{Cl}$ & $\mathbf{n}$ & Rate & $95 \% \mathrm{Cl}$ & IRR & $95 \% \mathrm{Cl}$ & $P$ value \\
\hline $15-24^{*}$ & 3238 & 3070 & $\ldots$ & $\ldots$ & $\ldots$ & $\ldots$ & $\ldots$ & $\ldots$ & $\ldots$ & $\ldots$ & $\ldots$ \\
\hline $25-34$ & 2788 & 4453 & 5 & 45 & 6 to 84 & 1 & 6 & 0 to 17 & 8.0 & 1 to 94 & 0.035 \\
\hline $55-64$ & 964 & 3053 & 14 & 363 & 173 to 553 & 12 & 98 & 43 to 154 & 3.7 & 2 to 8 & $<0.001$ \\
\hline$\geq 65$ & 748 & 1550 & 20 & 668 & 376 to 960 & 28 & 452 & 285 to 619 & 1.5 & 1 to 3 & 0.177 \\
\hline Total $^{*}$ & 16756 & 24806 & 74 & 110 & 85 to 136 & 47 & 47 & 34 to 61 & 2.3 & 2 to 3 & $<0.001$ \\
\hline Standardised $\dagger$ & & & & 153 & 129 to 177 & & 51 & 37 to 65 & 3.0 & 2 to 4 & $<0.001$ \\
\hline
\end{tabular}

${ }^{*}$ Ethics approval not obtained for those aged $<18$ years. However, calculated rates include the whole population.

†Age-standardised rate, standardised to WHO world population (rate per 100000 population/year). 


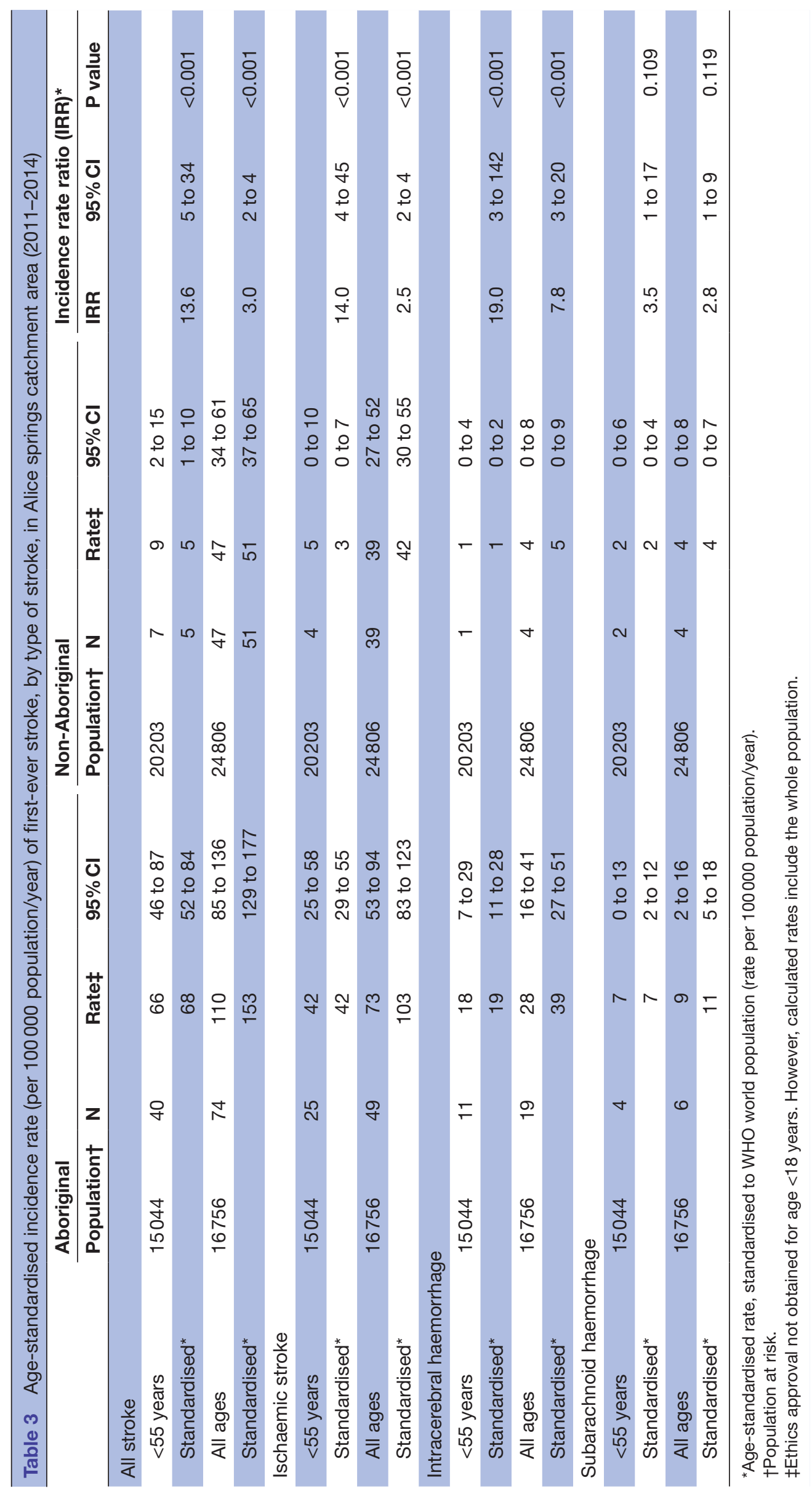




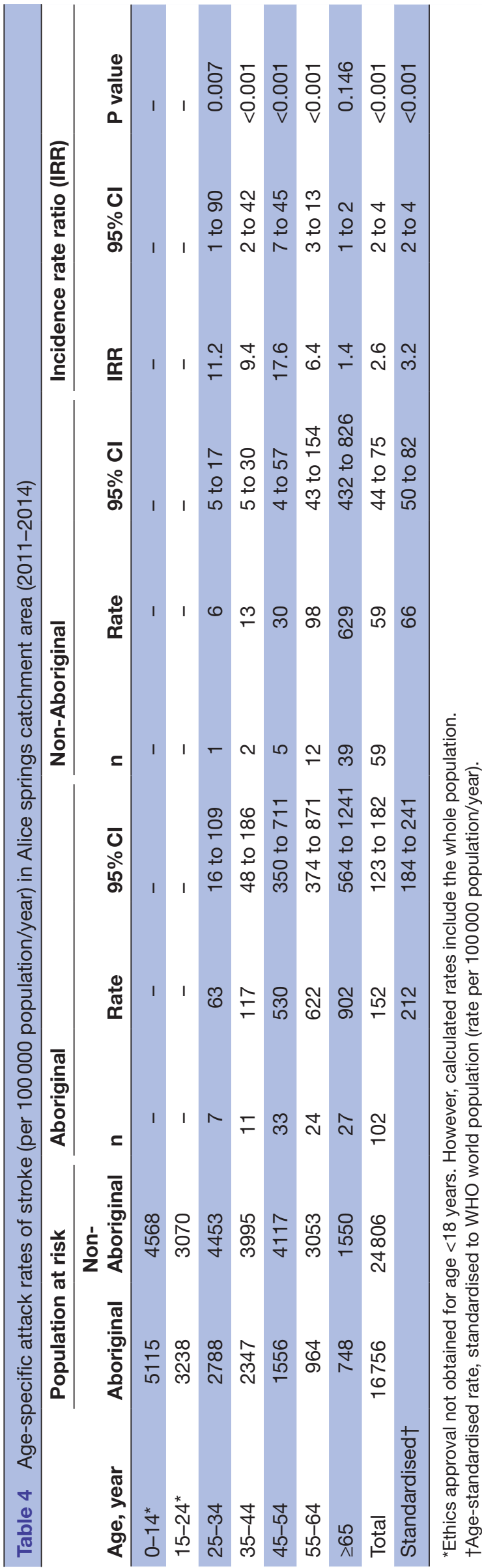

$11 \%$ underwent complete intra-and extracranial vessel imaging, 56\% had carotid duplex ultrasound only, and $33 \%$ had no vascular imaging. Of patients presenting with first-ever IS, 16 (18.1\%) had known atrial fibrillation prior to admission. Of the remaining 72 patients without pre-existing known atrial fibrillation, transthoracic echocardiography was performed in $51(70.8 \%)$ and cardiac rhythm monitoring (24hours Holter monitor or cardiac telemetry) in $29(40.3 \%)$ patients. Of 23 patients with ICH, $9 \%$ had intracranial vessel imaging.

In patients without pre-existing known atrial fibrillation, transthoracic echocardiogram was performed more frequently in Aboriginal patients (32/39) with first-ever IS than in non-Aboriginal patients $(19 / 33,82.1 \%$ vs $57.6 \%$, $\mathrm{p}=0.023)$. Otherwise, we were unable to detect any differences in the frequency of investigations being performed in Aboriginal patients with incident stroke when compared with non-Aboriginal patients. Vessel imaging (CT angiography or carotid duplex ultrasound) was performed in $52.1 \%$ of Aboriginal patients (39/74), compared with $59.6 \%$ of non-Aboriginal patients $(28 / 47, \mathrm{p}=0.549)$. Cardiac rhythm monitoring was performed in $38.4 \%$ of Aboriginal patients (15/39) and $39.4 \%$ of non-Aboriginal patients $(13 / 33)$ with first-ever IS without pre-existing known atrial fibrillation ( $\mathrm{p}=0.936)$.

The age-standardised incidence of IS was over twofold greater in the entire Aboriginal population than in the entire non-Aboriginal population and 14-fold greater in the Aboriginal population aged $<55$ years compared with the non-Aboriginal population of the same age (table 3 ). The incidence of ICH was almost eightfold greater in the entire Aboriginal population of all ages, and 19-fold greater in Aboriginal population aged $<55$ years compared with the non-Aboriginal population of the same age (table 3). Approximately one-quarter of all incident strokes in Aboriginal patients were ICH; this being threefold that of non-Aboriginal patients (table 5). In Aboriginal patients with ICH, $63 \%$ of ICH were determined to be hypertensive in aetiology (table 5). The aetiology of IS remained undetermined in a significant proportion of both Aboriginal (42.9\%) and non-Aboriginal patients $(61.5 \%$, table 5$)$.

\section{Potential for receipt of acute interventions}

No patients received thrombolysis or endovascular thrombectomy, as reperfusion therapies were not available for patients with stroke at ASH during the study period. Of 88 patients presenting with first-ever IS, we identified 16 patients ( $18.1 \%$ of whom one third were Aboriginal) who appeared to be eligible for treatment with intravenous thrombolysis, having presented within 4.5 hours of symptom onset.

\section{In-hospital case fatality and rate of death related to stroke}

In-hospital case fatality appeared to be higher in Aboriginal people $(23.0 \%)$ than non-Aboriginal people $(10.6 \%$; $\mathrm{p}=0.086)$, although not statistically significant at conventional levels. However, the crude and age-standardised 
Table 5 Proportion of incident (first-ever) stroke by stroke subtype in Alice springs catchment area (2011-2014)

\begin{tabular}{|c|c|c|c|}
\hline & \multirow{2}{*}{$\begin{array}{l}\text { Total } \\
\mathrm{n}(\%)\end{array}$} & \multirow{2}{*}{$\begin{array}{l}\text { Aboriginal } \\
\mathrm{n}(\%)\end{array}$} & \multirow{2}{*}{$\begin{array}{l}\text { Non-Aboriginal } \\
\mathrm{n}(\%)\end{array}$} \\
\hline & & & \\
\hline & $n=121$ & $\mathrm{n}=74$ & $\mathrm{n}=47$ \\
\hline Large artery atherosclerosis & $5(5.7)$ & $2(4.1)$ & $3(7.8)$ \\
\hline Cardioembolism & $21(23.9)$ & $17(34.7)$ & $4(10.3)$ \\
\hline Other determined aetiology & $3(3.4)$ & $1(2.0)$ & $2(5.1)$ \\
\hline Undetermined aetiology & $45(51.1)$ & $21(42.9)$ & $24(61.5)$ \\
\hline Intracerebral haemorrhage $(\mathrm{ICH}) \dagger$ & $23(19.0)$ & $19(25.7)$ & $4(8.5)$ \\
\hline Hypertension & $12(52.1)$ & $12(63.1)$ & $0(0)$ \\
\hline Amyloid angiopathy & $4(17.4)$ & $1(5.3)$ & $3(75.0)$ \\
\hline Aneurysm & $6(60.0)$ & $4(66.7)$ & $2(50.0)$ \\
\hline Amyloid angiopathy & $1(10.0)$ & $1(16.7)$ & $0(0)$ \\
\hline Other determined aetiology & $0(0.0)$ & $0(0)$ & $0(0)$ \\
\hline Undetermined aetiology & $3(30.0)$ & $1(16.7)$ & $2(50.0)$ \\
\hline
\end{tabular}

${ }^{*}$ Stroke aetiology classified by Trial of ORG 10172 in Acute Stroke Treatment ${ }^{14}$ criteria, with the percentage of subtypes representing the proportion of those with ischaemic stroke.

†Stroke aetiology classified by SMASH-U ICH${ }^{15}$ classification, with the percentage of subtypes representing the proportion of those with ICH.

rates of incident stroke resulting in death were significantly greater; fivefold greater in the Aboriginal than non-Aboriginal samples (table 1 ).

\section{DISCUSSION}

We present the first detailed stroke-neurologist curated data on stroke incidence and subtypes in remote Aboriginal Australians within a well-defined healthcare network system. Our results demonstrate significant disparities in age-standardised stroke incidence rates and in-hospital death rates between Aboriginal and non-Aboriginal populations. Disparities were especially marked in patients aged $<55$ years. Furthermore, Aboriginal patients appeared to more commonly have ICH than non-Aboriginal patients; this form of stroke has much poorer outcomes than for IS.

Aboriginal patients had stroke at an earlier age than non-Aboriginal people, and this disparity appeared greater than that reported previously, ${ }^{56}$ although CIs are wide. The disparities in the younger Aboriginal patients is consistent with earlier onset of cardiovascular comorbidity in the Aboriginal population, which is reported to occur on average 10-20 years earlier than in the nonAboriginal population. ${ }^{1819}$ Indeed, a recent study showed that the stroke risk in Aboriginal patients with atrial fibrillation aged under 60 years was three times higher than their non-Aboriginal counterparts, with an even higher disparity for fatal stroke. ${ }^{20}$ This is reflected in our study's findings; although only diabetes mellitus and hypercholesterolaemia were shown to have a significantly greater crude prevalence in Aboriginal patients, we found similar if not greater prevalence of all cardiovascular risk factors in Aboriginal patients, despite the 17-year age gap between the median age of first-ever stroke in Aboriginal and nonAboriginal patients. Of note is that $6.8 \%$ of Aboriginal stroke patients had a history of rheumatic heart disease, a condition that is endemic in this population generally and in this region specifically. ${ }^{21} 22$

Notably, our incidence rates for Aboriginal people are generally greater than those found in other studies where the composition of the population is less remote. ${ }^{5}$ This finding might be explained by greater rates of cardiovascular comorbidities in Aboriginal people residing in remote areas, compared with those in non-remote areas, ${ }^{23}$ although we acknowledge the relatively small sample size and overlapping confidence intervals. Furthermore, it appears that Aboriginal people are not only at greater risk of first stroke, but also of recurrent stroke. This may be a consequence of marked inequalities in access to and appropriateness of secondary prevention, particularly in remote Aboriginal communities. ${ }^{19}$

The proportion of stroke attributable to ICH was substantially greater in Aboriginal patients, comprising over $25 \%$ of all incident strokes, approximately threefold that of non-Aboriginal patients. The reason for this is unclear, but may be partly attributable to earlier-onset 
cardiovascular risk factors for $\mathrm{ICH},{ }^{20}$ along with dietary and lifestyle factors and the social determinants of health. ${ }^{19} 20$ Of note, the proportion of ICH in Aboriginal patients is similar to that observed in East Asian populations. ${ }^{24}$ This greater proportion of ICH, a type of stroke with greater mortality, ${ }^{25}$ also provides an explanation for the greater age-standardised rate of in-hospital death in Aboriginal patients than non-Aboriginal patients with incident stroke. This high stroke mortality is likely a major contributor to the life expectancy 'gap' between Aboriginal and non-Aboriginal Australians. ${ }^{2}$

An aetiological classification could not be determined for more than half of patients with IS; this reflects the high proportion of both Aboriginal and non-Aboriginal patients having incomplete investigation in remote Australia. Importantly, this highlights unmet need and inequity in access, which is particularly significant given the younger age profile of Aboriginal patients, which would generally be an indication for more extensive investigation to determine the aetiology of stroke. It is also notable that no patient received thrombolysis, as thrombolytic therapy for stroke was not available at ASH during the time period of the study; this has subsequently been introduced along with a region-specific stroke protocol.

Our study had several limitations. Given its retrospective nature, our results may be affected by incomplete data records, with six records unlocatable, and is subject to bias. Therefore, our findings can only be indirectly compared with prospective incidence studies. ${ }^{2526}$ Sample sizes in some age categories, including for older Aboriginal patients, are small, thereby reducing the precision of the incidence rates calculated. Suboptimal sensitivity of stroke coding may have also resulted in ascertainment bias (through false negatives), although our methods ensured that no false positives were included in our counts. In addition, underascertainment from remote communities may have occurred, either due to mild stroke syndromes or out-of-hospital fatal strokes. Although in an urban Australian stroke study, 96\% of all incident cases presented to hospital, ${ }^{27}$ the proportion of patients not presenting to hospital in this remote catchment is unknown and may have been higher than in urban settings. However, the well-defined nature of the 'ub and spoke' network, with the requirement that patients with stroke are transferred to ASH for imaging diagnosis and more comprehensive management makes this number likely to be small. ${ }^{4}$ In further support for the view that substantial underascertainment in the non-Aboriginal population is unlikely, we found similar age-adjusted incidence rates in the non-Aboriginal population (47 per 100000 ) to those in a recent 'ideal' rural Australian stroke study (50 per 100000$).{ }^{28}$ If there was underascertainment in Aboriginal patients, the disparities we identified are likely to be underestimated. Incomplete documentation and diagnostic evaluation meant that in a large proportion of cases, stroke aetiology could not be determined. Furthermore, the relatively small sample size limited the ability to determine whether conventional risk factors explained the disparities in incidence.

This study also has a number of strengths. It comprises the largest population-based dataset of stroke in Aboriginal people utilising all available clinical and radiological data for case ascertainment, enabling all strokes to be adjudicated. While our findings of disparities in stroke incidence rates are similar to previously published data, ${ }^{6-8}$ we combine a larger cohort with detailed case analysis. Well-defined population-based methodology, with rigorous case analysis, allowed more accurate stroke ascertainment and phenotyping than previous codingbased studies. Previous studies have been unable to provide these insights, either due to low case numbers, imprecise stroke phenotyping due to the use of administrative data without accompanying clinical evaluation, or datasets almost 20 years old. ${ }^{5-10}$ Lastly, to our knowledge, we have provided the first validation for the positive predictive value of ICD-10-AM codes for stroke in a remote setting.

We have identified areas of unmet need in healthcare services, and provide a foundation on which to explore the efficacy of health intervention on stroke incidence and outcomes in Aboriginal Australians. Partly as a result of this study, in the 5 years following the study period, a stroke protocol has been introduced, including Telestrokesupported intravenous thrombolytic therapy for IS, as well as Telestroke-supported retrieval $1319 \mathrm{~km}$ distance to Adelaide in South Australia for endovascular thrombectomy or surgical intervention where appropriate. These interventions have facilitated improved access to reperfusion therapy, investigation, aetiological classification and secondary prevention of stroke in Central Australia. In partnership with Aboriginal researchers, governing bodies, medical services and community groups, these results are being used to inform the development of culturally responsive stroke prevention and management tools for Aboriginal communities in Central Australia. Further research will be undertaken to evaluate the efficacy of these interventions.

\section{Author affiliations}

${ }^{1}$ Department of Neurology, Royal Adelaide Hospital, Adelaide, South Australia, Australia

${ }^{2}$ Department of Medicine, School of Clinical Sciences, Monash University, Clayton, Victoria, Australia

${ }^{3}$ Department of Neurology, Royal Prince Alfred Hospital, Camperdown, New South Wales, Australia

${ }^{4}$ Aboriginal Research Unit, South Australian Health and Medical Research Institute, Adelaide, South Australia, Australia

${ }^{5}$ Department of Medicine, Alice Springs Hospital, Alice Springs, Northern Territory, Australia

${ }^{6}$ School of Population and Global Health, The University of Western Australia, Perth, Western Australia, Australia

${ }^{7}$ Adelaide Medical School, Faculty of Health and Medical Sciences, The University of Adelaide, Adelaide, South Australia, Australia

${ }^{8}$ Department of Neurology, Royal Darwin Hospital, Casuarina, Northern Territory, Australia

${ }^{9}$ Department of Medicine and Neurology, Melbourne Brain Centre at Royal Melbourne Hospital, Parkville, Victoria, Australia 
${ }^{10}$ Stroke Research Programme, The University of Adelaide, Adelaide, South Australia, Australia

Acknowledgements We acknowledge the Aboriginal people included in this study who own these data. We also gratefully acknowledge the Aboriginal researchers, communities and Elders, ethics committees and organisations who provided oversight of the study, including the Aboriginal Medical Services Alliance Northern Territory and the Wardliparingga Aboriginal Research Unit within the South Australian Health and Medical Research Institute. We acknowledge scholarship (AHB; 1169269), fellowship (AGT; 1042600) and Synergy Grant (TJK, AGT, JMK; 1182071) support from the National Health and Medical Research Council and the Heart Foundation (JMK).

Contributors TJK, AGT and $A B$ devised the project and main conceptual ideas with the assistance of $\mathrm{KM}, \mathrm{SB}, \mathrm{JB}$ and SK. KG designed the study protocol. AHB, BG, DB, SC and TJK collected data. AHB, KG, AGT and TJK performed data analysis. AHB took the lead in preparing the manuscript, with substantial input from TJK, AGT and JK. All authors (including GAD) provided critical feedback and helped shape the research, analysis and manuscript. TJK and AB supervised the project.

Funding This work was supported by the National Heart Foundation of Australia Vanguard Award 100603.

Map disclaimer The depiction of boundaries on this map does not imply the expression of any opinion whatsoever on the part of BMJ (or any member of its group) concerning the legal status of any country, territory, jurisdiction or area or of its authorities. This map is provided without any warranty of any kind, either express or implied.

Competing interests None declared.

Patient consent for publication Not required.

Ethics approval Ethics approval was obtained from the Central Australian Human Research Ethics Committee (HREC-15-338) and the Aboriginal Health Research Ethics Committee of the Aboriginal Health Council of South Australia (04-15-629).

Provenance and peer review Not commissioned; externally peer reviewed.

Data availability statement Data may be obtained from a third party and are not publicly available. Authors are willing to be contacted directly regarding potential data sharing. As this research involves Aboriginal Peoples, data sharing could occur only following ethics approval from all relevant human research ethics committees. This is consistent with the CARE Principles for Indigenous Data Governance.

Open access This is an open access article distributed in accordance with the Creative Commons Attribution Non Commercial (CC BY-NC 4.0) license, which permits others to distribute, remix, adapt, build upon this work non-commercially, and license their derivative works on different terms, provided the original work is properly cited, appropriate credit is given, any changes made indicated, and the use is non-commercial. See: http://creativecommons.org/licenses/by-nc/4.0/.

\section{ORCID iDs}

Anna H Balabanski http://orcid.org/0000-0003-3209-3101

Amanda G Thrift http://orcid.org/0000-0001-8533-4170

Judith Katzenellenbogen http://orcid.org/0000-0001-5287-5819

\section{REFERENCES}

1 Australian Institute of Health and Welfare. Australian burden of disease study: impact and causes of illness and death in Australia 2011. Australian burden of disease study series No. 3. BOD 4. Canberra: AlHW, 2016.

2 Life tables for Aboriginal and Torres Strait Islander Australians, 20152017. 2018. Australian Bureau of statistics. Available: https://www. abs.gov.au/ausstats/abs@.nsf/latestProducts/3302.0.55.003Media\% 20Release152015-2017 [Accessed May 20, 2019].

3 Cruz Rivera S, Kyte DG, Aiyegbusi OL, et al. Assessing the impact of healthcare research: a systematic review of methodological frameworks. PLoS Med 2017; 14:e1002370.

4 Paul CL, Sanson-Fisher R, Stewart J, et al. Being sorry is not enough: the sorry state of the evidence base for improving the health of Indigenous populations. Am J Prev Med 2010;38:566-8.
5 Balabanski AH, Newbury J, Leyden JM, et al. Excess stroke incidence in young Aboriginal people in South Australia: pooled results from two population-based studies. Int J Stroke 2018;13:811-4.

6 You J, Condon JR, Zhao Y, et al. Stroke incidence and case-fatality among Indigenous and non-Indigenous populations in the Northern Territory of Australia, 1999-2011. Int J Stroke 2015;10:716-22.

7 Katzenellenbogen JM, Knuiman MW, Sanfilippo FM, et al. Prevalence of stroke and coexistent conditions: disparities between Indigenous and nonindigenous Western Australians. Int J Stroke 2014;9 Suppl A100:61-8

8 Katzenellenbogen JM, Vos T, Somerford P, et al. Burden of stroke in Indigenous Western Australians: a study using data linkage. Stroke 2011;42:1515-21.

9 Pepper EM, Cadilhac DA, Pearce DC, Burrow J, et al. Stroke among Indigenous Australians at Royal Darwin Hospital, 2001-02. Med J Aust 2006;184:195.

10 Kilkenny MF, Harris DM, Ritchie EA, et al. Hospital management and outcomes of stroke in Indigenous Australians: evidence from the 2009 acute care national stroke audit. Int J Stroke 2013;8:164-71.

11 Australian Institute of Health and Welfare. Australia's health 2018. Australia's health series no. 16. AUS 221. Canberra: AlHW, 2018.

12 Australian Bureau of Statistics. Census of Population and Housing - Counts of Aboriginal and Torres Strait Islander Australians, Cat no 2002. Canberra: ABS, 2011. http://www.abs.gov.au/websitedbs/ censushome.nsf/home/Census. (Accessed May 20, 2019).

13 Hatano S. Experience from a multicentre stroke register: a preliminary report. Bull World Health Organ 1976;54:541-53.

14 Adams HP, Bendixen BH, Kappelle LJ, et al. Classification of subtype of acute ischemic stroke. definitions for use in a multicenter clinical trial. TOAST. trial of ORG 10172 in acute stroke treatment. Stroke 1993;24:35-41.

15 Meretoja A, Strbian D, Putaala J, et al. SMASH-U: a proposal for etiologic classification of intracerebral hemorrhage. Stroke 2012;43:2592-7.

16 Ahmad OB, Boschi-Pinto C, Lopez AD. Age standardization of rates: a new WHO standard. GPE discussion paper series: no. 31. Geneva: World Health Organization, 2001.

17 Research Data Alliance International Indigenous Data Sovereignty Interest Group. CARE Principles for Indigenous Data Governance." The Global Indigenous Data Alliance, 2019. Available: www.GIDAglobal.org [Accessed July 30, 2020].

18 Fitzgerald X, Herceg A, Douglas K, et al. Cardiovascular disease risk assessment in an Aboriginal community-controlled health service: comparing algorithms. Aust J Prim Health 2020;26:281.

19 Brown A, Kritharides L. Overcoming cardiovascular disease in Indigenous Australians. Med J Aust 2017;206:10-12.

20 Nedkoff L, Kelty EA, Hung J, et al. Differences in stroke risk and cardiovascular mortality for Aboriginal and other Australian patients with atrial fibrillation. Med J Aust 2020;212:215-21.

21 Cannon J, Bessarab DC, Wyber R, et al. Public health and economic perspectives on acute rheumatic fever and rheumatic heart disease. Med J Aust 2019;211:250-2.

22 Katzenellenbogen JM, Bond-Smith D, Seth RJ, et al. The end rheumatic heart disease in Australia study of epidemiology (erase) project: data sources, case ascertainment and cohort profile. Clin Epidemiol 2019;11:997-1010.

23 Australian Institute of Health and Welfare. Cardiovascular disease, diabetes and chronic kidney disease- Australian facts: Aboriginal and Torres Strait Islander people. cardiovascular, diabetes and chronic kidney disease series No. 5. cat. No. CDK 5. Canberra: AlHW, 2015.

24 Wei JW, Arima H, Huang Y, et al. Variation in the frequency of intracerebral haemorrhage and ischaemic stroke in China: a national, multicentre, hospital register study. Cerebrovasc Dis 2010;29:321-7.

25 Thrift AG, Dewey HM, Sturm JW, et al. Incidence of stroke subtypes in the North East Melbourne stroke incidence study (NEMESIS): differences between men and women. Neuroepidemiology 2009;32:11-18.

26 Sudlow CL, Warlow CP. Comparing stroke incidence worldwide: what makes studies comparable? Stroke 1996;27:550-8.

27 Leyden JM, Kleinig TJ, Newbury J, et al. Adelaide stroke incidence study: declining stroke rates but many preventable cardioembolic strokes. Stroke 2013;44:1226-31.

28 Newbury J, Kleinig T, Leyden J, et al. Stroke epidemiology in an Australian rural cohort (SEARCH). Int J Stroke 2017;12:161-8. 